\title{
A comparison of treatment modalities for nasal extranodal natural killer/T-cell lymphoma in early stages: The efficacy of CHOP regimen based concurrent chemoradiotherapy
}

\author{
Jianzhong Cao ${ }^{1, *}$, Shengmin Lan ${ }^{1, *}$, Liuhai Shen ${ }^{2}$, Hongwei $\mathrm{Si}^{2}$, Ning Zhang ${ }^{1}$, \\ Hongwei $\mathbf{L i}^{1}$, Ruyuan Guo ${ }^{1}$ \\ ${ }^{1}$ Department of Radiotherapy, Shanxi Cancer Hospital and Institute, Affiliated Hospital of Shanxi Medical University, Shanxi, \\ China \\ ${ }^{2}$ Department of Nuclear Medicine, The First Affiliated Hospital of Anhui Medical University, Hefei, Anhui Province, China \\ *These authors have contributed equally to this work
}

Correspondence to: Hongwei Si, email: sihw@163.com

Keywords: nasal extranodal natural killer/T-cell lymphoma, concurrent chemoradiotherapy

Received: July 28, $2016 \quad$ Accepted: November 07, $2016 \quad$ Published: November 25, 2016

\section{ABSTRACT}

This study was designed to evaluate the efficacy of several treatment modalities, including CHOP based concurrent chemoradiotherapy (CCRT), for the patients with stage IE or IIE nasal extranodal NK/T-cell lymphoma (nasal ENKL). The cases were retrieved between 2000 and $2010(n=94)$, and were followed to the end of February 2016. The patients were grouped into A (chemotherapy alone; CT alone), B (sequential treatment) and C (CCRT). For those with efficacy evaluation for overall treatment $(n=90)$, CR was attained in $60.0 \%(18 / 30), 69.8 \%(30 / 43)$ and $76.5 \%(13 / 17)$ patients in the group A, B and C, respectively. The 5-year OS rate was $35.2 \%, 41.9 \%$ and $70.6 \%$ in the group $A, B$ and $C$, respectively. For patients with early stage diseases (IE and IIE), the ECOG performance status and the Ann Arbor stage were significant prognostic factors for both OS and PFS. Among the stage IE patients, besides the ECOG performance status, three prognostic factors which related to treatments (treatment modalities, efficacy of initial and overall treatment) were significant against os or PFS. In conclusion, compared to chemotherapy alone and sequential treatment, nasal ENKL patients in early stages, especially stage IE, benefit the most from CHOP based concurrent chemoradiotherapy.

\section{INTRODUCTION}

Nasal extranodal natural killer/T-cell lymphoma (nasal ENKL), which strongly associated with EpsteinBarr virus infection, is relatively common in Asian and Latin American countries [1]. Although the patients initially have good performance status and low international prognostic index (IPI) scores [2], nasal ENKL is the most aggressive subtype of non-Hodgkin's lymphoma [3].

Because of the frequently expressed multidrug resistance (MDR) associated p-glycoprotein (P-gp), nasal ENKL patients usually do not efficiently respond to chemotherapy (CT), especially CHOP (cyclophosphamide, doxorubicin, vincristine and prednisone) or CHOP like regimens [4]. For the localized diseases in early stages, radiotherapy (RT) is considered as the front-line treatment [5], and usually produces a more rapid response and a higher complete remission rate (CR) [1]. However, RT alone is insufficient to improve overall survival (OS), and needed to be combined with $\mathrm{CT}$ in an appropriate sequence [6]. Among the combined treatment modalities, concurrent chemoradiotherapy (CCRT) using MDRunrestricted agents [7] and radiation sensitizers [8,9] can improve the CR rate to $73.3 \%$ and $77 \%$, respectively [10]. However, the optimal treatment of early stages nasal ENKL remains to be determined.

To evaluate the relatively rare disease, it is not easy to perform a prospective trial. Therefore, we performed this retrospective study to compare the efficacy of CCRT, sequential treatments and $\mathrm{CT}$ alone for nasal ENKL in early stages. 


\section{RESULTS}

\section{Patient characteristics and treatment}

Between 2000 and 2011, a total of 99 patients were enrolled, and five cases were excluded for lost to follow up. Patient characteristics are listed in Table 1. Median age of the patients was 42.0 years (range 14 to $74 \mathrm{y}$ ), and the majority were younger than 60 years $(n=85,90.4 \%)$. There were 34, 43 and 17 patients in the group A (CT alone), $\mathrm{B}$ (sequential treatment) and C (CCRT), respectively. The percentages of patients with an ECOG performance status of $0-1$ were $67.6 \%(23 / 34), 86.0 \%(37 / 43)$ and $88.2 \%$ $(15 / 17)$ in the group A, B and C, respectively. In the group $\mathrm{B}, 11$ patients were treated with RT followed by CT $(\mathrm{RT}+\mathrm{CT})$, and 32 patients were treated with $\mathrm{CT}$ followed by RT $(\mathrm{CT}+\mathrm{RT})$.

Among the group A, B and C, except for the new staging system $\left(x^{2}=13.694, p=0.007\right)$ and the Ann Arbor stage $\left(x^{2}=9.557, p=0.007\right)$, other patient characteristics did not exist significant difference, including IPI $\left(x^{2}=7.106\right.$, $p=0.078)$, age $(\mathrm{F}=2.066, p=0.133)$, gender $\left(x^{2}=0.237\right.$, $p=0.947)$, and ECOG performance status $\left(x^{2}=4.442\right.$, $p=0.118$ ). The differences among the groups were mainly from the group A, which enrolled more stage IIE patients than other groups. Between the group B and C, the new staging system $\left(x^{2}=5.202, p=0.074\right)$ and the Ann Arbor stage $\left(x^{2}=1.140, p=0.286\right)$ did not have significant difference.

Radiotherapy ( $\mathrm{n}=60$ ) was given by the Varian 6-MV linear accelerator (median radiation dose 50Gy, range 30-70Gy). The median dose of group B and C was both $50 \mathrm{~Gy}$, and was higher than 50 Gy in $13 / 43$ and 6/17 patients $\left(x^{2}=0.014, p=0.907\right)$, respectively. In the group $\mathrm{B}$, $7 / 34$ patients accepted intensity modulated radiotherapy (IMRT), and no patients in the group $\mathrm{C}$ accepted the treatment.

For the treatments of $\mathrm{CT}(\mathrm{n}=94), 77$ patients were administrated 1-6 cycles (median: 4 cycles) of $\mathrm{CHOP}$ (or CHOP like) regimens ( $\mathrm{n}=21,39$ and 17 in the group $\mathrm{A}, \mathrm{B}$ and $\mathrm{C})$. Other patients accepted 1-6 cycles (median: 4 cycles) of BACOP (bleomycin, adriamycin, cyclophosphamide, oncovin and prednisone, 11 and 2 patients in the group A and B), and 2-13 cycles (median: 5.5 cycles) CAV (cyclophosphamide, doxorubicin and vincristine, 2 and 2 patients in the group A and B). All patients in group $\mathrm{C}$ accepted 1-8 cycles of $\mathrm{CHOP}$ regimens (median 3.5).

\section{Patterns of treatment failure}

Among the patients who failed to the treatments $(n=37)$, the patterns of failures were loco-regional and distant lymph node failure $(\mathrm{n}=20)$ and systemic failure $(n=9)$, and 8 patients encountered both lymph node and systemic failure. Extranodal failure were observed in bone marrow $(n=6)$, skin $(n=5)$, lung $(n=2)$, testis $(n=2)$, hypopharynx $(\mathrm{n}=2)$, brain $(\mathrm{n}=1)$, and colon $(\mathrm{n}=1)$.

When the disease recurred or progressed, salvage treatments were chemotherapy. The regimens included CHOP (or CHOP like, n=9), EPOCH (etoposide, doxorubicin, vincristine, cyclophosphamide and prednisone, $n=6$ ), IMVP-16 (ifosfamide, etoposide and methotrexate, $n=13$ ), DHAP (dexamethasone, cytarabine, and cisplatin, $\mathrm{n}=5$ ) and GEMOX (gemcitabine and oxaliplatin, $\mathrm{n}=4$ ) regimens.

\section{Treatment toxicity}

All treatments were tolerable in most patients. The most common toxicity was neutropenia which developed from chemotherapy, and the mucositis from radiotherapy. In Table 2, only $>2$ radiation mucositis of group $\mathrm{C}$ is significantly higher than other groups. In the group A and $\mathrm{B}$, four and three patients died of neutropenia associated infection, respectively. One patient in the group $\mathrm{C}$ died of treatment unassociated cerebral infarction.

\section{Treatment response}

Six patients did not have efficacy initial and/or overall treatment evaluations: 2 patients without initial evaluation achieved PR after overall treatments (group $\mathrm{B}, 1 / 2$ died), and 4 patients were not evaluated after both initial and overall treatments (group A, 2/4 died). For patients with initial treatment evaluations $(n=88$, Figure 1), CR were attained in $60.0 \%(18 / 30), 26.8 \%$ $(11 / 41)$ and $76.5 \%(13 / 17)$ patients in the group A, B and $\mathrm{C}$, respectively. For patients with overall treatment evaluations $(\mathrm{n}=90), \mathrm{CR}$ was attained in $60.0 \%(18 / 30)$, $69.8 \%(30 / 43)$ and $76.5 \%(13 / 17)$ patients in the group A, B and C, respectively. Overall response rates (ORR) to overall treatments were $90.0 \%$ (27/30), 97.7\% (42/43) and $94.1 \%(16 / 17)$ in the group A, B and C, respectively. In the group $\mathrm{B}, \mathrm{CR}$ rates to $\mathrm{CT}+\mathrm{RT}$ and $\mathrm{RT}+\mathrm{CT}$ were $75.0 \%$ (24/32) and 54.5\% (6/11), respectively. Among patients accepted CT $+\mathrm{RT}, \mathrm{CR}$ rate to initial treatment for chemotherapy was only $15.6 \%(5 / 32)$.

\section{Survivals and prognosis}

By the end of February 2016, survival and local recurrence information were collected $(n=94)$. The median observation times were 36.6 (range 6.7-179.5 months), 27.3 months (range 5.9-178.6) and 63.4 months (range 11.9-151.8) for the group A, B and C, respectively. Tumor progression occurred within a median time of 49.6 months (range 9.1-97.3 months). In the group A, B and $\mathrm{C}$, recurrence was observed in 23/34 (67.6\%), 8/43 $(18.6 \%)$ and $3 / 17(17.6 \%)$ patients, respectively. Fortytwo patients died within 6.0 to 178.0 months. There were 20/34 (58.8\%), 18/43 (41.9\%) and 4/17 (23.5\%) deaths in the group A, B and C, respectively. 
Table 1: Patient characteristics

\begin{tabular}{lcccccc}
\hline Characteristic & & Group A & Group B & Group C & $\boldsymbol{p}$ & All n (\%) \\
\hline Gender & Male & $14(82.4)$ & $33(76.7)$ & $27(79.4)$ & & $74(78.7)$ \\
& female & $3(17.6)$ & $10(23.3)$ & $7(20.6)$ & 0.947 & $20(21.3)$ \\
B symptoms & Absent & $10(58.8)$ & $25(58.1)$ & $23(67.7)$ & & $58(61.7)$ \\
& Present & $7(41.2)$ & $18(41.9)$ & $11(32.4)$ & 0.642 & $36(38.3)$ \\
Waldeyer's ring & Absent & $14(82.4)$ & $35(81.4)$ & $25(73.5)$ & & $74(78.7)$ \\
& Present & $3(17.6)$ & $8(18.6)$ & $9(26.5)$ & 0.712 & $20(21.3)$ \\
Local invasion & Absent & $9(52.9)$ & $14(32.6)$ & $19(55.9)$ & & $42(44.7)$ \\
& Present & $8(47.1)$ & $29(67.4)$ & $15(44.1)$ & 0.094 & $52(55.3)$ \\
LDH level & Normal & $15(88.2)$ & $37(86.0)$ & $30(88.2)$ & & $82(87.2)$ \\
Ann Arbor stage & Abnormal & $2(11.8)$ & $6(14.0)$ & $4(11.8)$ & 1.000 & $12(12.8)$ \\
& IE & $16(94.1)$ & $36(83.7)$ & $20(58.8)$ & & $72(76.6)$ \\
New staging & IIE & $1(4.5)$ & $7(16.3)$ & $14(41.2)$ & 0.007 & $22(23.4)$ \\
& Limited IE & $9(52.9)$ & $10(23.3)$ & $9(26.5)$ & & $28(29.8)$ \\
Extensive IE & $7(41.2)$ & $26(60.5)$ & $11(32.4)$ & & $44(46.8)$ \\
IPI score & IIE & $1(5.9)$ & $7(16.3)$ & $14(41.2)$ & 0.007 & $22(234)$ \\
performance status & 0 & $9(52.9)$ & $34(79.1)$ & $28(82.4)$ & & $71(75.5)$ \\
& 22 & $2(11.8)$ & $6(31.6)$ & $11(32.4)$ & 0.118 & $19(20.2)$ \\
\hline
\end{tabular}

Table 2: Toxicity of treatments

\begin{tabular}{lccccccc}
\hline & \multicolumn{2}{c}{ Group A } & \multicolumn{2}{c}{ Group B } & \multicolumn{2}{c}{ Group C } & $\boldsymbol{x}^{\mathbf{2}}$ \\
\hline Toxicity & $\leq \mathbf{2}$ & $>\mathbf{2}$ & $\leq \mathbf{2}$ & $>\mathbf{2}$ & $\leq \mathbf{2}$ & $>\mathbf{2}$ & \\
\hline Hematologic & & & & & & & \\
Neutropenia & $20(58.8)$ & $14(41.2)$ & $27(62.8)$ & $16(37.2)$ & $10(58.8)$ & $7(41.2)$ & 0.008 \\
Anemia & $32(94.1)$ & $2(5.9)$ & $38(88.4)$ & $5(11.6)$ & $13(76.5)$ & $4(23.5)$ & 3.214 \\
Thrombocytopenia & $32(94.1)$ & $2(5.9)$ & $41(95.3)$ & $2(4.7)$ & $14(82.4)$ & $3(17.6)$ & 1.554 \\
Non-hematologic & & & & & & & \\
Nausea & $32(94.1)$ & $2(5.9)$ & $39(90.7)$ & $4(9.3)$ & $15(88.2)$ & $2(11.8)$ & 0.561 \\
Vomiting & $34(100)$ & $0(0)$ & $43(100)$ & $0(0)$ & $16(94.1)$ & $1(5.9)$ & 2.764 \\
Diarrhea & $34(100)$ & $0(0)$ & $43(100)$ & $0(0)$ & $17(100)$ & $0(0)$ & - \\
Anorexia & $34(100)$ & $0(0)$ & $43(100)$ & $0(0)$ & $17(100)$ & $0(0)$ & - \\
Constipation & $34(100)$ & $0(0)$ & $43(100)$ & $0(0)$ & $17(100)$ & $0(0)$ & - \\
Radio-mucositis & $34(100)$ & $0(0)$ & $43(100)$ & $0(0)$ & $13(76.5)$ & $4(23.5)$ & $11.426^{* *}$ \\
Radiodermatitis & $34(100)$ & $0(0)$ & $43(100)$ & $0(0)$ & $16(94.1)$ & $1(5.9)$ & 2.764 \\
\hline
\end{tabular}

$*: \mathrm{p}<0.05 ; * *: \mathrm{p}<0.01$. 
5-year OS and progression-free survival (PFS) rates are listed in Table 3. Among the treatment groups, both OS $\left(x^{2}=7.086, p=0.029\right)$ and PFS $\left(x^{2}=7.378\right.$, $p=0.025)$ had significant difference. In the multivariate Cox regression (conditional forward) against OS, the ECOG performance status (odds ratio 2.2, 95\% CI 1.4 3.5, p=0.001) and the Ann Arbor stage (odds ratio $2.9,95 \%$ CI $1.5 \sim 5.6, \mathrm{p}=0.001$ ) showed statistical significance (Figure 2). In the Cox regression against PFS, the ECOG performance status (odds ratio 2.3, 95\% CI 1.5 3.6, $\mathrm{p}=0.000$ ) and the Ann Arbor stage (odds ratio $1.8,95 \%$ CI 1.2 2.7, p=0.002) had statistical significance (Figure 3 ).

In the group B, for CT+RT and RT+CT, 5-year OS rates were $41.3 \%$ and $58.4 \%$, and 5-year PFS rates were $39.0 \%$ and $24.2 \%$, respectively. The 5-year OS and PFS did not have significant differences between CT+RT and RT $+C T$ treatment $(p=0.593$ and $p=0.140)$. The median overall survival times for $\mathrm{CT}+\mathrm{RT}$ and $\mathrm{RT}+\mathrm{CT}$ were both 52.6 months, and the median progression-free survival times for the two treatment modalities were 44.3 and 32.6 months, respectively.

\section{Statistical analysis for stage IE disease}

Only limited cases in stage IIE were enrolled (14, 7 and 1 patients in the group A, B and C), and none of the influential factors was significant against OS or PFS.

There were 20, 36 and 16 stage IE patients in the group $\mathrm{A}, \mathrm{B}$ and $\mathrm{C}$, respectively. The 5-year OS rates were $50.7 \%, 53.9 \%$ and $75.0 \%\left(x^{2}=3.599, \mathrm{p}=0.165\right)$, and the 5-year PFS rates were $40.0 \%, 44.7 \%$, and $71.8 \%\left(x^{2}=3.972, \mathrm{p}=0.137\right)$ in the group $\mathrm{A}, \mathrm{B}$ and $\mathrm{C}$, respectively. The multivariate Cox regression test against PFS indicated that the treatment modalities (odds ratio 2.1, 95\% CI 1.3 3.4, $\mathrm{p}=0.003$ ) and the efficacy of overall treatment (odds ratio $3.0,95 \% \mathrm{CI}$ 2.0 4.6, $\mathrm{p}=0.000$ ) were significant factors. In the Cox regression test against $\mathrm{OS}$, the ECOG performance status (odds ratio 2.2, 95\% CI 1.1 4.2, $\mathrm{p}=0.022$ ) and
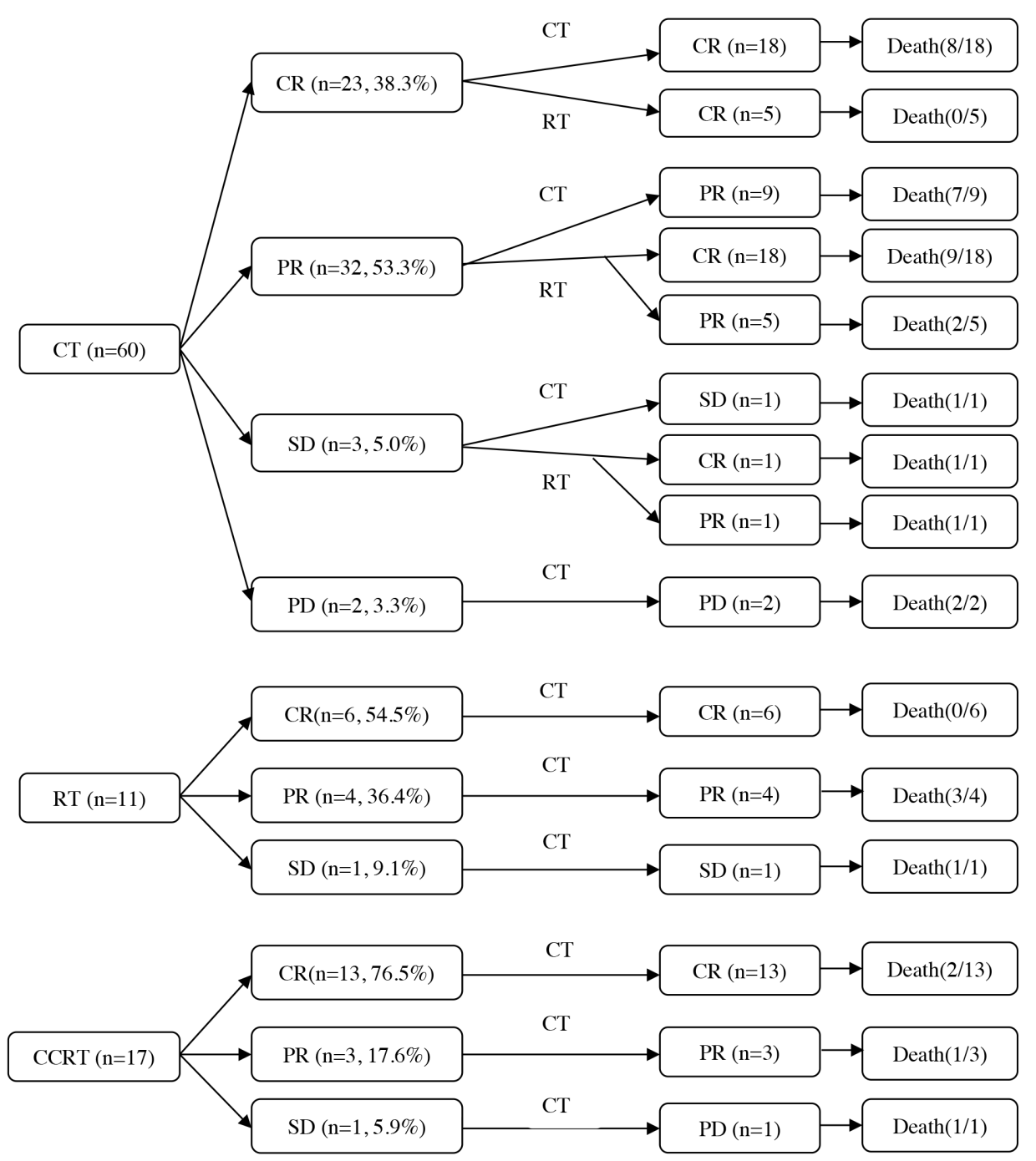

Figure 1: Treatment characteristics of patients $(n=88)$ after initial and overall treatment. 
Table 3: Survival analysis

\begin{tabular}{|c|c|c|c|c|c|c|c|c|}
\hline & & $\mathbf{N}$ & 5-year OS(\%) & $\begin{array}{c}\text { Median } \\
\text { (months) }\end{array}$ & $p$ & 5-year PFS(\%) & $\begin{array}{c}\text { Median } \\
\text { (months) }\end{array}$ & $p$ \\
\hline \multirow[t]{2}{*}{ Gender } & Male & 74 & 45.8 & 53.9 & 0.479 & 40.7 & 36.2 & 0.559 \\
\hline & Female & 20 & 42.8 & 45.6 & & 39.8 & 33.2 & \\
\hline \multirow[t]{2}{*}{ Age (years) } & $\leq 60$ & 85 & 43.2 & 52.6 & 0.580 & 38.0 & 33.2 & 0.526 \\
\hline & $>60$ & 9 & 66.7 & NA & & 66.7 & 76.6 & \\
\hline Radiation & $<50$ & 24 & 45.2 & 53.9 & 0.858 & 43.4 & 44.3 & 0.200 \\
\hline Dose (Gy) & $\geq 50$ & 36 & 58.6 & NA & & 67.3 & NA & \\
\hline \multirow[t]{2}{*}{ B symptoms } & Absent & 58 & 42.5 & 52.6 & 0.354 & 37.9 & 28.3 & 0.287 \\
\hline & Present & 36 & 47.1 & 45.6 & & 44.9 & 40.8 & \\
\hline Waldeyer's & Absent & 74 & 47.5 & 54.2 & 0.712 & 43.1 & 33.5 & 0.675 \\
\hline ring & Present & 20 & 39.7 & 52.6 & & 31.5 & 36.2 & \\
\hline Local & Absent & 42 & 50.8 & 66.1 & 0.442 & 45.0 & 33.5 & 0.500 \\
\hline invasion & Present & 52 & 38.7 & 45.6 & & 36.0 & 36.2 & \\
\hline \multirow[t]{2}{*}{ LDH level } & Normal & 82 & 48.7 & 54.2 & 0.490 & 43.1 & 36.2 & 0.405 \\
\hline & Abnormal & 12 & 0 & 33.7 & & $0 \%$ & 25.6 & \\
\hline \multirow{2}{*}{$\begin{array}{l}\text { Ann Arbor } \\
\text { stage }\end{array}$} & IE & 72 & 57.5 & 129.4 & 0.000 & 49.9 & 49.0 & 0.000 \\
\hline & IIE & 22 & 10.9 & 16.1 & & 11.3 & 16.1 & \\
\hline \multirow[t]{3}{*}{ New staging } & Limited IE & 28 & 73.8 & NA & 0.000 & 63.6 & 76.6 & 0.000 \\
\hline & Extensive IE & 44 & 44.0 & 53.9 & & 38.9 & 40.8 & \\
\hline & IIE & 22 & 10.9 & 16.1 & & 11.3 & 16.1 & \\
\hline \multirow[t]{3}{*}{ IPI score } & 0 & 71 & 47.4 & 56.8 & 0.885 & 41.9 & 61.6 & 0.842 \\
\hline & 1 & 22 & 37.5 & 45.0 & & 33.7 & 40.9 & \\
\hline & 2 & 1 & 0.0 & 12.0 & & 0.0 & 12.0 & \\
\hline $\begin{array}{l}\text { ECOG } \\
\text { performance }\end{array}$ & $0-1$ & 75 & 56.4 & 66.1 & 0.000 & 49.2 & 49.0 & 0.000 \\
\hline status & $\geq 2$ & 19 & 7.2 & 16.5 & & 6.3 & 12.5 & \\
\hline Initial & $\mathrm{CT}$ & 66 & 37.7 & 37.4 & 0.048 & 30.1 & 28.8 & 0.038 \\
\hline \multirow[t]{2}{*}{ treatment } & RT & 11 & 58.4 & NA & & 24.2 & 14.0 & \\
\hline & CCRT & 17 & 70.6 & NA & & 67.6 & NA & \\
\hline Treatment & CT only & 34 & 35.2 & 35.7 & 0.029 & 29.8 & 22.0 & 0.025 \\
\hline \multirow[t]{2}{*}{ modalities } & $\begin{array}{l}\text { Combined } \\
\text { therapy }\end{array}$ & 43 & 41.9 & 52.6 & & 36.0 & 33.5 & \\
\hline & CCRT & 17 & 70.6 & NA & & 67.6 & NA & \\
\hline
\end{tabular}

NA: Not arrive.

the efficacy of initial treatment (odds ratio $1.6,95 \% \mathrm{CI}$ $1.0 \sim 2.5, \mathrm{p}=0.030$ ) were significant factors.

\section{DISCUSSION}

In this study, the most characteristics of early stages ENKL patients were balanced between the treatment groups, except that the new staging system and the Ann Arbor stage of group A (enrolled more stage IIE patients) were different from that of other groups. Our results indicate that, among all patients, the ECOG performance status and the Ann Arbor stage are both significant against OS or PFS. Among the stage IE patients, besides the ECOG performance status, three factors (treatment modalities, efficacy of initial and overall treatment) related to therapy are significant against OS or PFS. Because $\mathrm{CHOP}$ based concurrent chemoradiotherapy can produce a higher CR rate and a longer 5-year OS (or 5-year PFS) rate than chemotherapy alone or sequential treatment, the CCRT treatment is a better modality for early stages nasal ENKL patients, especially for those in stage IE. 
In the past, RT alone was the first-line treatment of nasal ENKL (5-year OS rate about 40\%) [11]. After it was classified as a lymphoma, chemotherapy became the firstline treatment modality [12]. Although some patients could be cured by CHOP (or CHOP-like) based chemotherapy [13], nasal ENKL frequently fails to respond to the regimens [14]. In the study from Wang et al [15], CHOP based chemotherapy, as an induction treatment, could produce a CR rate of $31.8 \%$. In our patients treated with CT alone, additional chemotherapies could not efficiently convert them from PR to CR. This is consistent with the consensus that some nasal ENKL patients can benefit from the initial treatment of CHOP regimens, but not additional ones [4]. New regimens, for example L-asparaginase and gemcitabine regimen, were reported to be effective for nasal ENKL patients (2-year OS rate: 87.1\%) [16-18]; however, the regimens needed to be evaluated further.

Although radiotherapy usually produced a rapid treatment response, only 11 patients in this nasal ENKL cohort were initially treated by radiotherapy, and achieved a CR rate of $54.5 \%(6 / 11)$. After initial treatment of chemotherapy, RT could convert 18/23 (78.3\%) patients from PR to CR. Additionally, although poor responders to $\mathrm{CT}$ tended to accept RT in our hospital, the 5-year OS rates to $\mathrm{CT}+\mathrm{RT}$ and $\mathrm{RT}+\mathrm{CT}(38 \%$ and $58 \%)$ were comparable to other studies [12], and were higher than CT alone $(35.2 \%)$. Above all, our paradigm interfered with treatment selection more or less, and the efficacy of RT should be further evaluated.

Currently, CCRT had been regarded as a treatment option for localized diseases [9]. Using MDR-unrestricted agents [8], radiation sensitizers [7] or shrinking-field radiation strategy [19] to induce antitumor effect, a higher 5-year OS rate could be achieved (73\%, 78.6\% and $80 \%$, respectively). In our study, CHOP based CCRT could even produce a comparable 5-year OS and PFS rate (70.6\% and 67.6\%). Furthermore, except radiation mucositis, the toxicity profiles of CCRT for this cohort were also comparable to other groups, and are consistent with these CCRT

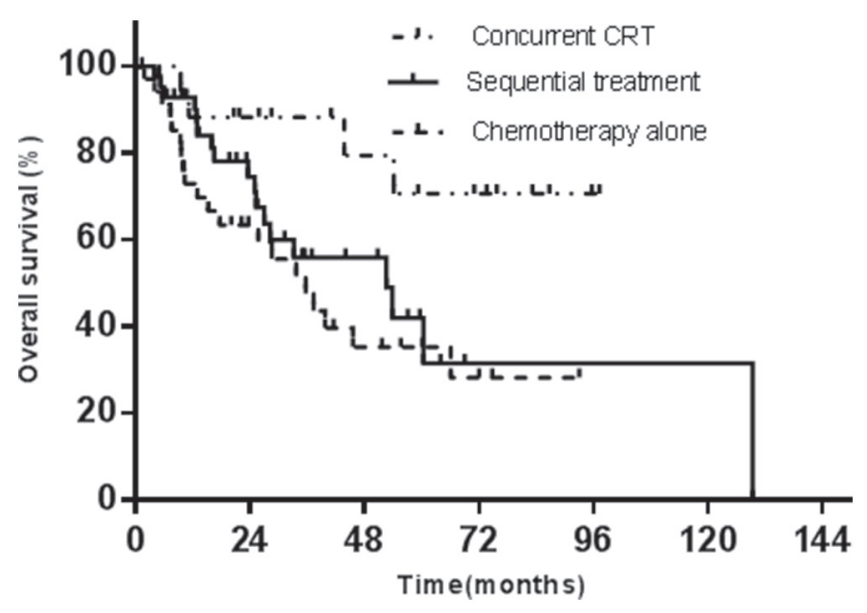

Figure 2: The initial treatment modalities against OS.

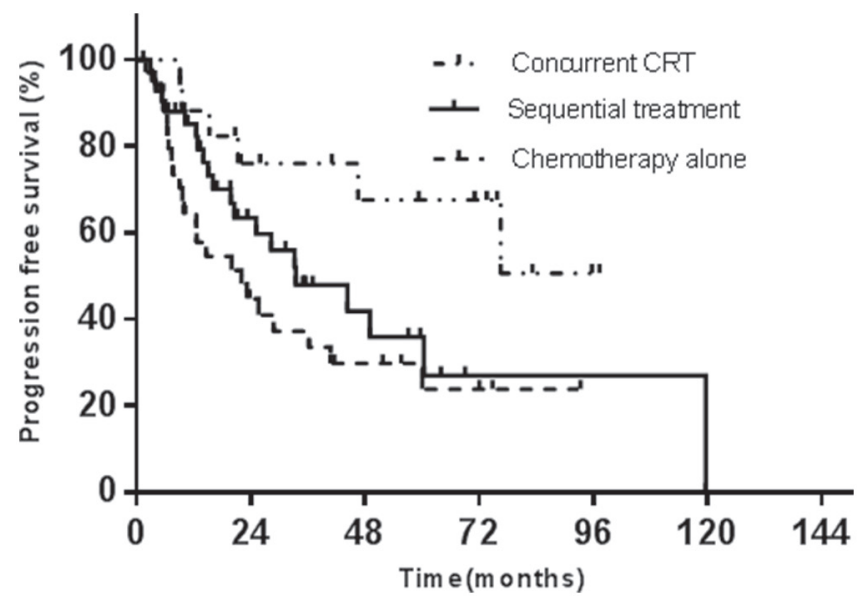

Figure 3: The initial treatment modalities against PFS. 
studies. Therefore, it seems that, for patients with nasal ENKL in early stages, the initial treatment of CHOP based CCRT is efficacious, and is less influenced by the frequently expressed P-glycoprotein (P-gp).

Our results can be explained by the study on advanced breast cancer [20]. P-gp, an ATP dependent membrane transporter which pumps cytotoxic drugs out of cells, is coded by the MDR1 (ABCB1) gene. MDR1 transcription can be started at 2 promoters: a major downstream promoter (DSP) and a minor upstream promoter (USP). Although transcripts from USP are associated with translating polyribosomes, their low concentration makes the amount of P-gp insufficient to affect the response of cells to an initial chemotherapy [20].

Additionally, among patient characteristics, only the Ann Arbor stage and the new stage were not balanced among the treatment groups. However, according to our results, the two stage systems would obviously affect the prognosis of the patients. When stratified by the Ann Arbor stage, 5-year OS and PFS rates were dramatically decreased in stage IIE patients (Table 3). Furthermore, stratified IE patients with the new stage system, the two rates for extension disease were lower than that of limited disease (Table 3). These results supported the prognostic value of the two stage systems, and coincided with other studies $[21,22]$. Therefore, it is possible that our results could be influenced by the poor prognosis of stage IIE patients, especially the results from group A (recruited more stage IIE patients). However, our results from stage IE patients confirmed the results from all patients, and indicated CCRT is superior to other treatment modalities. Because only one stage IIE patient was in the CCRT group, the response of stage IIE patients to $\mathrm{CHOP}$ based CCRT should be verified in future.

In conclusion, compared to chemotherapy alone and sequential treatment, patients with nasal ENKL in early stages, especially stage IE, benefit the most from CHOP based concurrent chemoradiotherapy. This treatment strategy can attain a comparable CR rate to other CCRT studies.

\section{PATIENTS AND METHODS}

\section{Patients}

Nasal ENKL cases in stage IE and IIE (Ann-Arbor stage [23]) were retrieved from the files of the Cancer Hospital of Shanxi Province between 2000 and 2011. All patients were diagnosed according to the morphological and immunohistological criteria recommended by the World Health Organization classification [24]. Additionally, the patients were scored and restaged according to the international prognostic index (IPI) and the new staging system [21], respectively. Our protocol was approved by the ethics committee at the Cancer
Hospital of Shanxi Province, and signed informed consent forms were obtained from all participants, who were consented to be followed.

Because there was no standard treatment for nasal ENKL, the paradigm of our hospital was not accordant, and CHOP regimens were most frequently administrated ones. Generally, for classifying as a lymphoma, chemotherapy was the first-line treatment, and only the poor responders would accept radiotherapy. After the study in 2006 from Li et al [25], more nasal ENKL patients accepted radiotherapy than before $(75 \%$ vs $51 \%$, Fisher's exact test $\mathrm{p}=0.022$ ), but still not the first choice.

From medical records or by telephone, the patients were followed to the end of February 2016, and were grouped into A (CT alone), B (sequential treatment) and C (CCRT) according to treatment modalities. The radiation fields of limited stage IE diseases included the bilateral nasal cavity, bilateral ethmoid sinuses, and ipsilateral maxillary sinus. For extensive stage IE patients, the fields were extended to adjacent involved structures. For stage IIE diseases, bilateral cervical lymph node areas were also covered. Additionally, fields for Walder ring included the ring, adjacent involved organs or structures, and cervical lymph nodes.

Before treatments, the Eastern Cooperative Oncology Group (ECOG) performance status was evaluated. According to the revised response criteria for malignant lymphoma [26], response to initial treatment (CT, RT, or CCRT) was evaluated by physical examinations and computerized tomography obtained 3 to 4 weeks after the completion of treatments. Response to overall treatments was assessed 3 to 4 weeks later. In the CCRT arm, RT and CT began on the same day, and response was also assessed 3 to 4 weeks later.

Tumor responses were classified into complete remission $(\mathrm{CR})$, partial remission $(\mathrm{PR})$, stable disease (SD) and progressive disease (PD) based on a radiographic review of MRI or computed tomography.

\section{Statistical analysis}

PFS was measured from the day treatment began to the first event of either recurrence or death. OS was measured from the day of diagnosis to death from any cause. All data was inputted into the SPSS statistical software (version 10.01, SPSS Inc, Chicago, IL). KaplanMeier and Log-rank test were applied to calculate the survival rates and to compare survival curves, respectively. The Cox regression analysis was used to find out the significant prognostic factors for PFS or OS. $\mathrm{p}<0.05$ was considered as the significant level.

\section{CONFLICTS OF INTEREST}

None declared. 


\section{REFERENCES}

1. Lee J, Cho SG, Chung SM, Ryu MR, Kim SH, Jang HS, Choi BO. Retrospective analysis of treatment outcomes for extranodal NK/T-cell lymphoma (ENKL), nasal type, stage I-IIE: single institute experience of combined modality treatment for early localized nasal extranodal NK/T-cell lymphoma (ENKL). Ann Hematol. 2013; 92:333-43.

2. Kim SJ, Kim BS, Choi CW, Choi J, Kim I, Lee YH, Kim JS. Ki-67 expression is predictive of prognosis in patients with stage I/II extranodal NK/T-cell lymphoma, nasal type. Ann Oncol. 2007; 18:1382-87.

3. Hong J, Park S, Baek HL, Jung JH, Kang IG, Sym SJ, Park J, Ahn JY, Cho EK, Kim ST, Shin DB, Lee JH. Tumor cell nuclear diameter and CD30 expression as potential prognostic parameter in patients with extranodal NK/Tcell lymphoma, nasal type. Int J Clin Exp Pathol. 2012; 5:939-47.

4. Kohrt H, Advani R. Extranodal natural killer/T-cell lymphoma: current concepts in biology and treatment. Leuk Lymphoma. 2009; 50:1773-84.

5. Wang H, Li YX, Wang WH, Jin J, Dai JR, Wang SL, Liu YP, Song YW, Wang ZY, Liu QF, Fang H, Qi SN, Liu XF, $\mathrm{Yu} \mathrm{ZH}$. Mild toxicity and favorable prognosis of highdose and extended involved-field intensity-modulated radiotherapy for patients with early-stage nasal NK/Tcell lymphoma. Int J Radiat Oncol Biol Phys. 2012; 82:1115-21.

6. Guo Y, Lu JJ, Ma X, Wang B, Hong X, Li X, Li J. Combined chemoradiation for the management of nasal natural killer (NK)/T-cell lymphoma: elucidating the significance of systemic chemotherapy. Oral Oncol. 2008; 44:23-30.

7. Kim SJ, Kim K, Kim BS, Kim CY, Suh C, Huh J, Lee SW, Kim JS, Cho J, Lee GW, Kang KM, Eom HS, Pyo HR, et al. Phase II trial of concurrent radiation and weekly cisplatin followed by VIPD chemotherapy in newly diagnosed, stage IE to IIE, nasal, extranodal NK/T-Cell Lymphoma: Consortium for Improving Survival of Lymphoma study. J Clin Oncol. 2009; 27:6027-32.

8. Yamaguchi $M$, Tobinai $K$, Oguchi $M$, Ishizuka N, Kobayashi Y, Isobe Y, Ishizawa K, Maseki N, Itoh K, Usui N, Wasada I, Kinoshita T, Ohshima K, et al. Phase I/II study of concurrent chemoradiotherapy for localized nasal natural killer/T-cell lymphoma: Japan Clinical Oncology Group Study JCOG0211. J Clin Oncol. 2009; 27:5594-600.

9. Yamaguchi $M$, Tobinai $K$, Oguchi $M$, Ishizuka $N$, Kobayashi Y, Isobe Y, Ishizawa K, Maseki N, Itoh K, Usui N, Wasada I, Kinoshita T, Hotta T, et al. Concurrent chemoradiotherapy for localized nasal natural killer/Tcell lymphoma: an updated analysis of the Japan clinical oncology group study JCOG0211. J Clin Oncol. 2012; 30:4044-46.

10. Shimada K, Suzuki R. Concurrent chemoradiotherapy for limited-stage extranodal natural killer/t-cell lymphoma, nasal type. J Clin Oncol. 2010; 28:e229; author reply e230.
11. Kim GE, Cho JH, Yang WI, Chung EJ, Suh CO, Park KR, Hong WP, Park IY, Hahn JS, Roh JK, Kim BS. Angiocentric lymphoma of the head and neck: patterns of systemic failure after radiation treatment. J Clin Oncol. 2000; 18:54-63.

12. Kim TH, Kim JS, Suh YG, Cho J, Yang WI, Suh CO. The Roles of Radiotherapy and Chemotherapy in the Era of Multimodal Treatment for Early-Stage Nasal-Type Extranodal Natural Killer/T-Cell Lymphoma. Yonsei Med J. 2016; 57:846-54.

13. Lin HN, Liu CY, Pai JT, Chang FP, Yang CF, Yu YB, Hsiao LT, Chiou TJ, Liu JH, Gau JP, Tzeng CH, Chen PM, Hong YC. How to predict the outcome in mature T and NK cell lymphoma by currently used prognostic models? Blood Cancer J. 2012; 2:e93.

14. Wang B, Li XQ, Ma X, Hong X, Lu H, Guo Y. Immunohistochemical expression and clinical significance of P-glycoprotein in previously untreated extranodal NK/T-cell lymphoma, nasal type. Am J Hematol. 2008; 83:795-99.

15. Wang L, Xia ZJ, Huang HQ, Lu Y, Zhang YJ. Cyclophosphamide, doxorubicin, vincristine, and prednisone (CHOP) in the treatment of stage IE/IIE extranodal natural killer/T cell lymphoma, nasal type: 13-year follow-up in 135 patients. Int J Hematol. 2012; 96:617-23.

16. Yong W. Clinical study of 1-asparaginase in the treatment of extranodal NK/T-cell lymphoma, nasal type. Hematol Oncol. 2016; 34:61-68.

17. Wang JJ, Dong M, He XH, Li YX, Wang WH, Liu P, Yang JL, Gui L, Zhang CG, Yang S, Zhou SY, Shi YK. GDP (Gemcitabine, Dexamethasone, and Cisplatin) Is Highly Effective and Well-Tolerated for Newly Diagnosed Stage IV and Relapsed/Refractory Extranodal Natural Killer/TCell Lymphoma, Nasal Type. Medicine (Baltimore). 2016; 95:e2787.

18. Zhang L, Li S, Jia S, Nan F, Li Z, Cao J, Fan S, Zhang C, Su L, Wang J, Xue H, Zhang M. The DDGP (cisplatin, dexamethasone, gemcitabine, and pegaspargase) regimen for treatment of extranodal natural killer (NK)/T-cell lymphoma, nasal type. Oncotarget. 2016; 7:58396-58404. doi: 10.18632/oncotarget.11135.

19. Hattori Y, Murai T, Iwata H, Uchiyama K, Mimura M, Kato E, Murata R, Shibamoto Y. Chemoradiotherapy for localized extranodal natural killer/T-cell lymphoma, nasal type, using a shrinking-field radiation strategy: multiinstitutional experience. Jpn J Radiol. 2016; 34:292-99.

20. Raguz S, Randle RA, Sharpe ER, Foekens JA, Sieuwerts AM, Meijer-van Gelder ME, Melo JV, Higgins CF, Yagüe E. Production of P-glycoprotein from the MDR1 upstream promoter is insufficient to affect the response to first-line chemotherapy in advanced breast cancer. Int $\mathrm{J}$ Cancer. 2008; 122:1058-67.

21. Kim TM, Heo DS. Extranodal NK / T-cell lymphoma, nasal type: new staging system and treatment strategies. Cancer Sci. 2009; 100:2242-48. 
22. Yang Y, Zhang YJ, Zhu Y, Cao JZ, Yuan ZY, Xu LM, Wu JX, Wang W, Wu T, Lu B, Zhu SY, Qian LT, Zhang FQ, et al. Prognostic nomogram for overall survival in previously untreated patients with extranodal NK/T-cell lymphoma, nasal-type: a multicenter study. Leukemia. 2015; 29:1571-77.

23. A predictive model for aggressive non-Hodgkin's lymphoma. The International Non-Hodgkin's Lymphoma Prognostic Factors Project. N Engl J Med. 1993; 329:987-94.

24. Jaffe ES, Harris NL, Stein $H$, et al. World health organization classification of tumours. Lyon, France: IARC Press; 2001.
25. Li YX, Yao B, Jin J, Wang WH, Liu YP, Song YW, Wang SL, Liu XF, Zhou LQ, He XH, Lu N, Yu ZH. Radiotherapy as primary treatment for stage IE and IIE nasal natural killer/T-cell lymphoma. J Clin Oncol. 2006; 24:181-89.

26. Cheson BD, Pfistner B, Juweid ME, Gascoyne RD, Specht L, Horning SJ, Coiffier B, Fisher RI, Hagenbeek A, Zucca E, Rosen ST, Stroobants S, Lister TA, et al, and International Harmonization Project on Lymphoma. Revised response criteria for malignant lymphoma. J Clin Oncol. 2007; 25:579-86. 